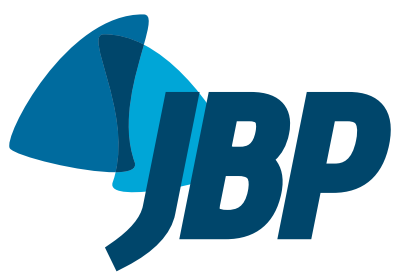

\title{
Recent transmission of drug-resistant Mycobacterium tuberculosis in a prison population in southern Brazil
}

\author{
Ana Julia Reis ${ }^{1}$, Simone Maria Martini de David², Luciana de Souza Nunes ${ }^{3}$,
} Andreia Rosane de Moura Valim³ ${ }^{3}$ Lia Gonçalves Possuelo ${ }^{3}$

1. Universidade Federal do Rio Grande, Rio Grande, Rio Grande do Sul, Brasil.

2. Laboratório Central do Estado do Rio Grande do Sul (IPB-LACEN/RS), Rio Grande do Sul, Brasil.

3. Programa de Pós-Graduação em Promoção da Saúde, Centro de Pesquisa e Treinamento em Biotecnologia - CPTBio Universidade de Santa Cruz do Sul, Santa Cruz do Sul, Rio Grande do Sul, Brasil.

Submitted: 21 January 2016

Accepted: 19 April 2016

Study carried out at the Universidade Federal do Rio Grande, Rio Grande, and at the Universidade de Santa Cruz do Sul,

\section{ABSTRACT}

We conducted a cross-sectional, retrospective study, characterized by classical and molecular epidemiology, involving $M$. tuberculosis isolates from a regional prison in southern Brazil. Between January of 2011 and August of 2014, 379 prisoners underwent sputum smear microscopy and culture; 53 (13.9\%) were diagnosed with active tuberculosis. Of those, $8(22.9 \%)$ presented with isoniazid-resistant tuberculosis. Strain genotyping was carried out by 15 -locus mycobacterial interspersed repetitive unitvariable-number tandem-repeat analysis; $68.6 \%$ of the patients were distributed into five clusters, and $87.5 \%$ of the resistant cases were in the same cluster. The frequency of drug-resistant tuberculosis cases and the rate of recent transmission were high. Our data suggest the need to implement an effective tuberculosis control program within the prison system.

Keywords: Tuberculosis; Prisons; Molecular epidemiology. Santa Cruz do Sul (RS) Brasil.

Chief among the factors contributing to the increasing incidence of tuberculosis in prison populations are: male gender; a low level of education; coming from a disadvantaged community; illicit drug use; a high prevalence of HIV infection; limited access to health care; overcrowded, poorly lit, and poorly ventilated cells; and a lack of information on tuberculosis. ${ }^{(1,2)}$ In addition, studies have shown that both a higher frequency of prior arrests and length of incarceration are directly associated with a higher incidence of this disease. ${ }^{(3,4)}$

In recent years, the incidence of tuberculosis has decreased worldwide, with a $45 \%$ reduction in the number of cases between 1990 and 2012. According to the World Health Organization, Brazil ranks 19th among the 22 countries that collectively account for $80 \%$ of all cases of tuberculosis worldwide. ${ }^{(5)}$ However, the incidence rates of the disease in Brazil and in the Brazilian state of Rio Grande do Sul have remained unchanged. In 2013, a total of 78,628 cases were reported in Brazil, and, of those, $6,378(8.1 \%)$ were reported for the prison population. In the state of Rio Grande do Sul, 6,917 cases were reported in 2014 , with $9.4 \%$ of those cases being reported for the prison population. ${ }^{(6)}$

In the prison population, it is possible to determine recent transmission of tuberculosis, characterized by the identification of genetically similar strains, within the prison facilities. Through active surveillance and the aid of molecular biology methods, the clonal relationship among strains can be determined, which is useful for epidemiological investigations, as well as for identification of genetically related strains and their spread among the prison population. ${ }^{(7)}$

The increasing incidence of cases of tuberculosis caused by drug-resistant strains of Mycobacterium tuberculosis is directly associated with inappropriate treatment or treatment nonadherence. Delayed detection of the disease, in patients with resistance, allows continuing transmission of these strains in a given population. $(8,9)$

M. tuberculosis genotyping is a useful tool for epidemiological studies, as well as for identifying clonal spread, any highly prevalent strains, and outbreaks. Among the current genotyping techniques, mycobacterial interspersed repetitive units-variable number of tandem repeats (MIRU-VNTR) has been used because it has similar discriminatory power to that of RFLP and because it employs PCR, which results in reduced completion time and reduced complexity when compared with RFLP. ${ }^{(10)}$

The objective of the present study was to determine the epidemiological profile of cases of tuberculosis in a prison in southern Brazil, by using classical and molecular epidemiology.

We conducted a cross-sectional, retrospective study of $M$. tuberculosis isolates from patients diagnosed with tuberculosis in the Santa Cruz do Sul Regional Prison, in the city of Santa Cruz do Sul, Rio Grande do Sul, Brazil, between January of 2011 and August of 2014. This is a medium-sized prison with health care staff. During the study period, 873 sputum smears were performed, accounting for 379 convicts; of those, 53 were diagnosed with tuberculosis in prison, indicating a prevalence of 80

Correspondence to:

Lia Gonçalves Possuelo. Universidade de Santa Cruz do Sul, Avenida Independência, 2293, Universitário, CEP 96815-900, Santa Cruz do Sul, RS, Brasil.

Tel.: 5551 8471-3720. E-mail: liapossuelo@unisc.br

Financial support: This study received financial support from the Brazilian Ministério da Ciência, Tecnologia e Inovação/Conse/ho Nacional de Desenvolvimento Cientifico e Tecnológico (MCTI/CNPq, National Ministry of Science, Technology, and Innovation/National Council for Scientific and Technological Development; Grant no. MCTI/CNPq/ UNIVERSAL 14/2014) and the Programa de Capacitação e Difusão Tecnológica/Fundação Estadual de Produção e Pesquisa em Saúde (PADCT/FEPPS, Education and Technology Diffusion Program/[Rio Grande do Sul] State Foundation for Health Science Research; Grant no. PADCT/FEPPS/2014). 
cases per 100,000 population. M. tuberculosis isolates were obtained from 35 different patients (66\%). The clinical isolates from those patients, which were subcultured in Ogawa-Kudoh medium and incubated at $37^{\circ} \mathrm{C}$ for $4-8$ weeks, were derived from a sample bank maintained by the Institute of Biological Research, Rio Grande do Sul State Central Laboratory. The 35 isolates were tested for susceptibility to isoniazid, ethambutol, rifampin, and pyrazinamide by the method of proportions ${ }^{(11)}$ and were genotyped by a PCR-based method using 15-locus MIRU-VNTR analysis. ${ }^{(12)}$

Demographic and prison-related data were obtained from the Integrated System of Penitentiary Information, which is regularly updated by prison officers, who provide data such as length of incarceration, history of incarceration, visits, number of inmates per cell, and changes of cells. The clinical and laboratory data of the patients were collected from the Rio Grande do Sul State Central Laboratory and the Santa Cruz do Sul municipal tuberculosis outpatient clinic. The epidemiological variables analyzed included age, gender, level of education, HIV infection, cell block, length of incarceration, history of incarceration, total length of incarceration, and number of changes of cells. The degree of relatedness among strains (genotype numbers) was compared by constructing a dendrogram. (13) The epidemiological, clinical, and prison-related data were evaluated with the IBM SPSS Statistics software package, version 20.0 (IBM Corp.,
Armonk, NY, USA). Values are presented as means and standard deviations or as absolute numbers and proportions. Means were compared by the Student's t-test, and categorical variables were compared by Pearson's chi-square test. Values of $p \leq 0.05$ were considered significant. The research project was approved by the Research Ethics Committee of the Rio Grande do Sul State Foundation for Health Science Research (Ruling no. 984.264).

Of the 35 individuals included in the study, all were male $(100 \%)$, with a mean age of 33.2 years; 31 $(88.6 \%)$ had had 9 years of schooling (Table 1 ). A total of $28(80.0 \%)$ had been in prison for more than 3 years, and all $(100 \%)$ had been arrested more than once, with the mean number of times arrested being $8.9 \pm 5.2$. Data regarding changes of cell were obtained for 34 individuals, all of whom had changed cells more than once during their incarceration period. In terms of the spatial distribution of the tuberculosis cases within the prison facility, we found that 10 individuals $(27.8 \%)$ had remained longer in cell block $\mathrm{C}$ than in the other cell blocks.

With regard to clinical characteristics, HIV test results were available for 19 patients (52.8\%), 1 (5.3\%) of whom tested positive. There were 21 patients $(58.3 \%)$ with a positive AFB-smear and $35(100 \%)$ with a positive culture, and culture resulted in a $41.7 \%$ increase in sensitivity for the diagnosis of tuberculosis.

Table 1. Patient clinical, demographic, and prison-related characteristics by classification as cluster or non-cluster cases. ${ }^{a}$

\begin{tabular}{|c|c|c|c|c|}
\hline Variable & Cluster & Non-cluster & Total & $\mathbf{p}$ \\
\hline Age, years & $34.10 \pm 11.85$ & $31.40 \pm 7.75$ & $33.20 \pm 10.70$ & 0.49 \\
\hline \multicolumn{5}{|l|}{ Level of education } \\
\hline 9 years of schooling & $20(64.5)$ & $11(35.5)$ & $21(88.6)$ & \multirow{3}{*}{0.35} \\
\hline High school & $3(100.0)$ & $0(0.0)$ & $3(8.6)$ & \\
\hline Illiterate & $1(100.0)$ & $0(0.0)$ & $1(2.9)$ & \\
\hline \multicolumn{5}{|l|}{ Cell block } \\
\hline A & $7(77.8)$ & $2(22.2)$ & $9(25.7)$ & \multirow{4}{*}{0.07} \\
\hline B & $5(100.0)$ & $0(0.0)$ & $5(14.3)$ & \\
\hline C & $8(80.0)$ & $2(20.0)$ & $10(28.6)$ & \\
\hline$D$ & $2(33.3)$ & $4(66.7)$ & $6(17.1)$ & \\
\hline \multicolumn{5}{|l|}{ Length of incarceration } \\
\hline Up to 3 years & $3(42.9)$ & $4(57.1)$ & $7(20.0)$ & \multirow[t]{2}{*}{0.17} \\
\hline More than 3 years & $21(75.0)$ & $7(25.0)$ & $28(80.0)$ & \\
\hline \multicolumn{5}{|l|}{ Number of times arrested } \\
\hline Up to 10 times & $18(72.0)$ & $7(28.0)$ & $25(71.4)$ & \multirow[t]{2}{*}{0.68} \\
\hline More than 10 times & $6(60.0)$ & $4(40.0)$ & $10(28.6)$ & \\
\hline \multicolumn{5}{|c|}{ Number of inmates per cell } \\
\hline Up to 6 & $5(100.0)$ & $0(0.0)$ & $5(16.7)$ & \multirow[t]{2}{*}{0.28} \\
\hline More than 6 & $17(68.0)$ & $8(32.0)$ & $25(83.3)$ & \\
\hline \multicolumn{5}{|l|}{ Visits } \\
\hline Yes & $13(72.2)$ & $5(27.8)$ & $18(51.4)$ & \multirow[t]{2}{*}{0.72} \\
\hline No & $11(64.7)$ & $6(35.3)$ & $17(48.6)$ & \\
\hline \multicolumn{5}{|l|}{ Conjugal visits } \\
\hline Yes & $10(83.3)$ & $2(16.7)$ & $12(34.3)$ & \multirow[t]{2}{*}{0.25} \\
\hline No & $14(60.9)$ & $9(39.1)$ & $23(65.7)$ & \\
\hline
\end{tabular}

aValues expressed as $n(\%)$ or as mean \pm SD. 
Of the 35 isolates undergoing genotyping, $24(68.6 \%)$ were found to be grouped into five clusters, named from A to $E$, each containing 3 to 7 individuals (Figure 1 ). Patient clinical, demographic, and prison-related data, by classification as cluster or non-cluster cases, are presented in Table 1.

Of the 35 isolates assessed regarding their drug susceptibility profile, 8 (22.9\%) were isoniazid mono-resistant. A total of $87.5 \%$ of the resistant isolates were in the same cluster (D), with patients being distributed between cell blocks $A$ and $B$, which are located on the prison same wing. The two largest clusters, B and D, accounted for $52.0 \%$ of the strains and contained all cases of drug resistance.

Of the 35 patients whose isolates were tested for antimicrobial susceptibility, $28(80.0 \%)$ had been in prison for more than 3 years and all $(100 \%)$ had been arrested more than once, with the mean number of times arrested being $8.9 \pm 5.2$, a mean that is higher than that reported in a study conducted in southern Brazil. ${ }^{(14)}$

One of the major obstacles to tuberculosis control is the accurate and early detection of cases. The
$41.7 \%$ increase in sensitivity achieved by culture, when compared with smear microscopy, emphasizes the need to perform culture in order to increase the tuberculosis case detection rate. ${ }^{(14)}$

Although HIV testing is mandatory for patients with tuberculosis, HIV test results were available for only $52.8 \%$, with one case of HIV-tuberculosis coinfection being identified $(5.3 \%)$, a value that is lower than that reported in studies conducted in southern Brazil. ${ }^{(15,16)}$

Of the isolated strains, $24(68.6 \%)$ were found to be grouped into five clusters. In a study conducted in another prison in Rio Grande do Sul, $58.3 \%$ of the isolates had an identical genetic profile. ${ }^{(14)}$ Although this high rate of clustering suggests recent transmission, which might have occurred within the prison facility, the lack of studies of isolates obtained from the local extramural population is a limiting factor for the present analysis. $^{(17,18)}$

Isoniazid mono-resistance was identified in 8 isolates $(22.9 \%), 7(87.5 \%)$ of which were in the same cluster ( $p<0.05)$, supporting the hypothesis of recent transmission of the bacilli. ${ }^{(19,20)}$ The high resistance rate

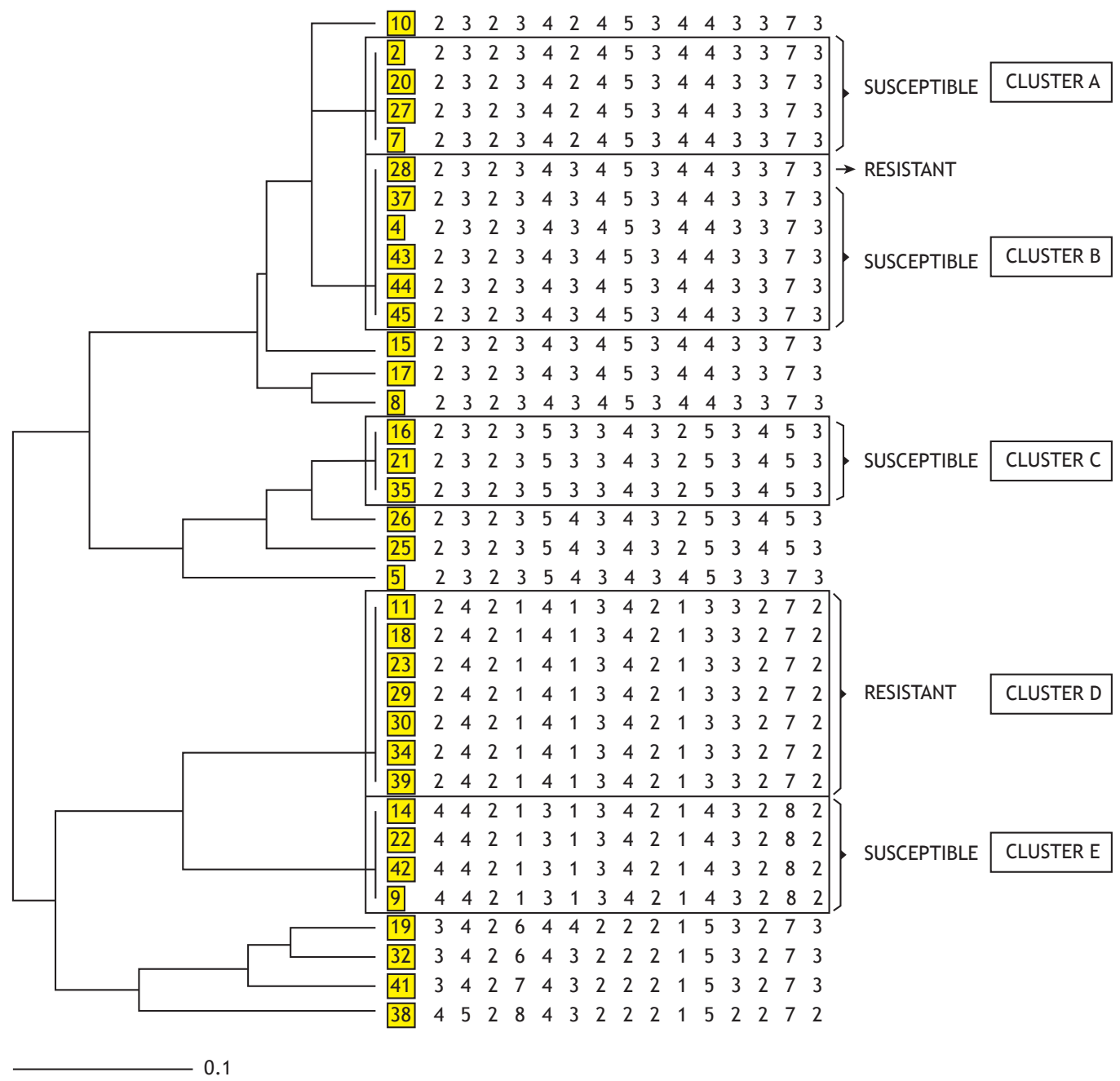

Figure 1. Dendrogram showing the clustering patterns associated with the drug susceptibility profile. 
observed in our study is higher than that reported in other studies. ${ }^{(7,14)}$ Drug resistance is considered to be a major problem in closed institutions, where outbreaks can reach epidemic proportions. ${ }^{(14)}$

Cluster $\mathrm{D}$, consisting of 7 patients who had resistance to isoniazid, was distributed between cell blocks $A$ and $B$ (both of which are located on the same prison wing and have a common exercise yard); although the individuals were not in the same cell, it should be taken into account that contact among inmates can take place in the exercise yard and that changes of cells and cell blocks are common.

The present study showed that the percentage of isoniazid-resistant isolates and the frequency of isolates sharing the same genotype were high. These data support the possibility that transmission of the bacillus occurred predominantly within the prison facility. Tuberculosis control in prison facilities depends on an effective disease control program, including active search for individuals with respiratory symptoms, prompt diagnosis, and directly observed treatment, within the prison system. In addition, providing continuing education for prison system workers and discussing the topic "prison health care" in other forums, such as community councils, can bring numerous benefits to tuberculosis control in prisons.

\section{ACKNOWLEDGMENTS}

We would like to thank Daniela Becker, Eloete Stahlecker, Vanda Hermes, Pedro Almeida da Silva, Augusto Weber, Graziela Hamann de Freitas, and João L. Scaini for their assistance in the various stages of the study.

\section{REFERENCES}

1. Brasil. Ministério da Saúde. Manual de Recomendações para o Controle da Tuberculose no Brasil. Brasília: Ministério da Saúde; 2011

2. Moreira TR, Fávero JL, Maciel EL. Tuberculose no sistema prisional capixaba. Rev Bras Pesq Saude. 2010;12(1):26-33.

3. Carbone Ada S, Paião DS, Sgarbi RV, Lemos EF, Cazanti RF, Ota $\mathrm{MM}$, et al. Active and latent tuberculosis in Brazilian correctional facilities: a cross-sectional study. BMC Infect Dis. 2015;15:24. http:// dx.doi.org/10.1186/s12879-015-0764-8

4. Urrego J, Ko Al, da Silva Santos Carbone A, Paião DS, Sgarbi RV, Yeckel CW, et al. The Impact of Ventilation and Early Diagnosis on Tuberculosis Transmission in Brazilian Prisons. Am J Trop Med Hyg 2015:93(4):739-46. http://dx.doi.org/10.4269/aitmh.15-0166

5. World Health Organization. Global Tuberculosis Report 2014 Geneva: World Health Organization; 2014

6. Brasil. Ministério da Saúde. Sistema de Informação de Agravos de Notificação [homepage on the Internet]. Brasília: Ministério da Saúde [updated 2015 Nov 16; cited 2015 Nov 28]. Banco de dados sobre tuberculose do DATASUS Available from: http://dtr2004.saude.gov. $\mathrm{br} /$ sinanweb/tabnet/dh? sinannet/tuberculose/bases/tubercbrnet.def

7. Kuhleis D, Ribeiro AW, Costa ER, Cafrune PI, Schmid KB, Costa $\mathrm{LL}$, et al. Tuberculosis in a southern Brazilian prison. Mem Inst Oswaldo Cruz. 2012;107(7):909-15. http://dx.doi.org/10.1590/S007402762012000700012

8. World Health Organization. Guidelines for the programmatic management of drug-resistant tuberculosis Geneva: World Health Organization; 2011.

9. Valim AR, Possuelo LG, Cafrune PI, Borges M, Ribeiro MO, Rossetti $\mathrm{ML}$, et al. Evaluation and Genotyping of Multidrug-Resistant Cases of Tuberculosis in Southern Brazil. Microb Drug Resist. 2006;12(3):18691. http://dx.doi.org/10.1089/mdr.2006.12.186

10. Pereira AM, Santos LC, Fernandes HB, Alves SL, Junqueira-Kipnis AP, Kipnis A. Análise molecular de Mycobacterium tuberculosis isolados de pacientes atendidos em Goiânia, Goiás, por meio do RFLP-IS6110 e do 15 loci MIRU-VNTR. Rev Patol Trop. 2013;42(3):275-88. http:// dx.doi.org/10.5216/rpt.v42i3.26925

11. Brasil. Ministério da Saúde. Manual Nacional de Vigilância Laboratorial da Tuberculose e outras Micobactérias. Brasília: Ministério da Saúde; 2008

12. Supply P. Multilocus Variable Number Tandem Repeat Genotyping of Mycobacterium tuberculosis: Technical Guide [monograph on the internet]. Lille: Institut de Biologie/Institut Pasteur de Lille; 2005 [updated 2015 Sep 10; cited 2015 Set 25]. [Adobe Acrobat document, 74p.]. Available from: http://www.miru-vntrplus.org/ MIRU/files/MIRU-VNTRtypingmanualv6.pdf

13. MIRU-VNTRplus [homepage on the Internet]. Münster: MIRUVNTRplus [updated 2015 Jun 16; cited 2015 Jun 30]. Available from: http://www.miru-vntrplus.org/MIRU/index.faces

14. Valença MS, Scaini JL, Abileira FS, Gonçalves CV, von Groll A, Silva PE. Prevalence of tuberculosis in prison: risk factors and molecula epidemiology. Int J Tuberc Lung Dis. 2015;19(10):1182-7. http:// dx.doi.org/10.5588/ijtld.15.0126

15. Valença MS, da Rocha JZ, Ramis IB, Carrion LL, Madruga C, de Macedo MB, et al. Improving tuberculosis control through the partnership between university and the health system. Rev Soc Bras Med Trop. 2012;45(4):491-5. http://dx.doi.org/10.1590/S003786822012005000004

16. Noguti EN, Leite CQ, Malaspina AC, Santos AC, Hirata RD, Hirata $\mathrm{MH}$, et al. Genotyping of Mycobacterium tuberculosis isolates from a low-endemic setting in northwestern state of Paraná in Southern Brazil. Mem Inst Oswaldo Cruz. 2010;105(6):779-85. http://dx.doi. org/10.1590/S0074-02762010000600008

17. Ibrayeva A, Kozhamkulov U, Raiymbek D, Alenova A, Igilikova S Zholdybayeva $\mathrm{E}$, et al. Molecular epidemiology of Mycobacterium tuberculosis strains circulating in the penitentiary system of Kazakhstan. Int J Tuberc Lung Dis. 2014;18(3):298-301. http://dx.doi. org/10.5588/ijtld.13.0558

18. Scholante Silva AB, Von Groll A, Félix C, Conceição FR, Spies FS, Scaini $\mathrm{CJ}$, et al. Clonal diversity of $\mathrm{M}$. tuberculosis isolated in a sea port city in Brazil. Tuberculosis (Edinb). 2009;89(6):443-7. http:// dx.doi.org/10.1016//.tube.2009.05.009

19. Toungoussova OS, Mariandyshev A, Bjune G, Sandven P, Caugant DA. Molecular epidemiology and drug resistance of Mycobacterium tuberculosis isolates in the Archangel prison in Russia: predominance of the W-Beijing clone family. Clin Infect Dis. 2003;37(5):665-72. http://dx.doi.org/10.1086/377205

20. Portugal I, Barreiro L, Vultos T, Macedo R, Furtado C, Fonseca Antunes $A$, et al. Molecular epidemiology of Mycobacterium tuberculosis in Lisbon. Rev Port Pneumol. 2008;14(2):239-59. http:// dx.doi.org/10.1016/S0873-2159(15)30233-6 